\title{
Longevidade pós-colheita de pseudobulbos com flores de Dendrobium nobile (Orchidaceae)
}

\author{
ADRIANE MARINHO DE ASSIS ${ }^{1}$; LARISSA ABGARIANI COLOMBO ${ }^{1}$; RICARDO TADEU DE FARIA ${ }^{1}$ \\ e INÊS CRISTINA DE BATISTA FONSECA ${ }^{1}$
}

\begin{abstract}
RESUMO
As orquídeas são consideradas plantas ornamentais de grande destaque na floricultura, sendo utilizadas como plantas de vaso e flores de corte. $\mathrm{O}$ objetivo deste trabalho foi avaliar a longevidade pós-colheita de pseudobulbos com flores de Dendrobium nobile, pelo uso de soluções conservantes, contendo diferentes concentrações de sacarose. Os tratamentos realizados foram: T1) água destilada; T2) sem água; T3) $10 \mathrm{gL}^{-1}$ de sacarose; T4) $20 \mathrm{gL}^{-1}$ de sacarose; T5) $30 \mathrm{gL}^{-1}$ de sacarose; T6) $40 \mathrm{gL}^{-1}$ de sacarose; $\mathrm{T} 7$ ) $80 \mathrm{gL}^{-1}$ de sacarose. A longevidade foi avaliada empregando-se o critério de notas. O delineamento experimental adotado foi o inteiramente casualizado, com sete tratamentos e dez repetições.As flores apresentaram longevidade de dez dias, a qual não foi influenciada pela utilização de soluções conservantes contendo sacarose.
\end{abstract}

Palavras-chave: orquídeas epífitas, sacarose, flor de corte.

\section{ABSTRACT \\ Post-harvesting longevity \\ of pseudo-bulbs storing Dendrobium nobile (Orchidaceae) flowers}

Orchids are considered ornamental plants of great importance in the flowers market, being used as poted plants or cut flower. The objective of this work was to evaluate the postharvest longevity of pseudo-bulbs of Dendrobium nobile wistli flowers, using preservant solutions with different concentrations of sucrose. Treatments used were as follows: T1) distilled water; T2) no water; T3) $10 \mathrm{gL}^{-1}$ of su- crose; T4) $20 \mathrm{gL}^{-1}$ of sucrose; T5) $30 \mathrm{gL}^{-1}$ of sucrose; T6) $40 \mathrm{gL}^{-1}$ of sucrose and T7) $80 \mathrm{gL}^{-1}$ of sucrose. Longevity was evaluated by a grading criteria. The experimental design was entirely casualized, with seven treatments and ten replications. Flower durability was ten days and longevity was not influenced by the preservant solutions containing sacharosis.

Key words: Orchids epiphytes, sacharosis, flowers for cutting.

\section{INTRODUÇÃO}

A família Orchidaceae possui aproximadamente 25.000 espécies que estão entre as plantas ornamentais mais apreciadas e de maior valor comercial (SILVA,1986). Apresentam grande potencial para utilização na floricultura, tanto como plantas de vaso como flores de corte, na composição de arranjos florais e buquês de noivas (LORENZI \& SOUZA,1996).

O gênero Dendrobium compreende cerca de 1.500 espécies. Originárias da China e do Himalaia, são consideradas plantas epífitas e multiplicam-se por divisão de touceiras ou divisão das inúmeras brotações laterais formadas nos pseudobulbos (LORENZI \& SOUZA, 2001). As plantas necessitam de regas regulares, local ventilado e temperatura entre 15 e $25^{\circ} \mathrm{C}$. Entre as espécies desse gênero, destaca-se a Dendrobium nobile Lind1., por sua variedade de cores e grande número de flores por planta (FARIA \& ILLG, 1993).

O sucesso comercial de uma flor de corte depende de sua qualidade estética, produção e longevidade após a colheita. O tratamento com soluções conservantes pode aumentar a longevidade e qualidade pós-colheita de flores de corte, em razão do fornecimento de açúcares e conservação da

\footnotetext{
${ }^{1}$ Universidade Estadual de Londrina (UEL), Departamento de Agronomia. Caixa Postal 6001, 86051- 990 Londrina (PR). E-mail: faria@uel.br.
} 
hidratação dos tecidos (HALEVY \& MAYAK, 1979). A utilização de açúcares, como sacarose e glicose, tem mostrado eficiência em prolongar a vida dessas flores (KETSA, 1989). Os açúcares translocados das soluções conservantes acumulam-se nas flores, aumentando a concentração osmótica, melhorando a capacidade de absorção e manutenção da turgescência das pétalas e favorecendo, desse modo, o balanço hídrico das flores de corte (HALEVY, 1976).

O objetivo deste trabalho foi avaliar a longevidade pós-colheita de pseudobulbos com flores da espécie Dendrobium nobile, mediante o uso de soluções conservantes, contendo sacarose em diferentes concentrações.

\section{MATERIAL E MÉTODOS}

O experimento foi realizado no Laboratório de Fitotecnia da UEL. Nos meses de outubro e novembro, um lote de 100 plantas da espécie Dendrobium nobile Lindl. foi selecionado no orquidário, por apresentar florescimento uniforme. Após cinco dias do início da abertura das flores, efetuou-se o corte em bisel de setenta pseudobulbos com quatro flores, deixando-os com $20 \mathrm{~cm}$ de comprimento. Em seguida, eles foram depositados em recipientes de vidro contendo $200 \mathrm{ml}$ de solução conservante em cada recipiente. A temperatura da sala oscilou entre 21 e $22^{\circ} \mathrm{C}$, apresentando $2.000 /$ lux de luminosidade. Os tratamentos realizados foram: T1) água destilada; T2) sem água; T3) $10 \mathrm{gL}^{-1} \mathrm{de}$ sacarose; T4) $20 \mathrm{gL}^{-1}$ de sacarose; T5) $30 \mathrm{gL}^{-1} \mathrm{de}$ sacarose; T6) $40 \mathrm{gL}^{-1}$ de sacarose; T7) $80 \mathrm{gL}^{-1}$ de sacarose. Acrescentaram-se três gotas de hipoclorito de sódio a $2,0 \%$ como agente bactericida, sendo as soluções conservantes renovadas a cada dois dias. O delineamento experimental utilizado foi o inteiramente casualizado, com dez repetições por tratamento. As avaliações da longevidade das flores foram realizadas diariamente, durante dez dias (Figura 1), segundo o seguinte critério de notas (CASTRO,1984): Nota 4: flor com características perfeitas para comercialização, túrgida, vistosa e sem manchas; Nota 3: flor com alguma característica alterada, mas ainda com qualidade comercial; Nota 2: flor com pétalas e sépalas levemente murchas e/ou manchadas, não adequada para a comercialização; Nota 1: flor com pétalas e sépalas murchas e manchadas, não adequada para a comercialização; Nota 0: flor com pétalas e sépalas ressecadas ou sem estas. As notas obtidas foram submetidas à análise da variância e as médias, comparadas pelo teste de Tukey, a 5\% de significância.

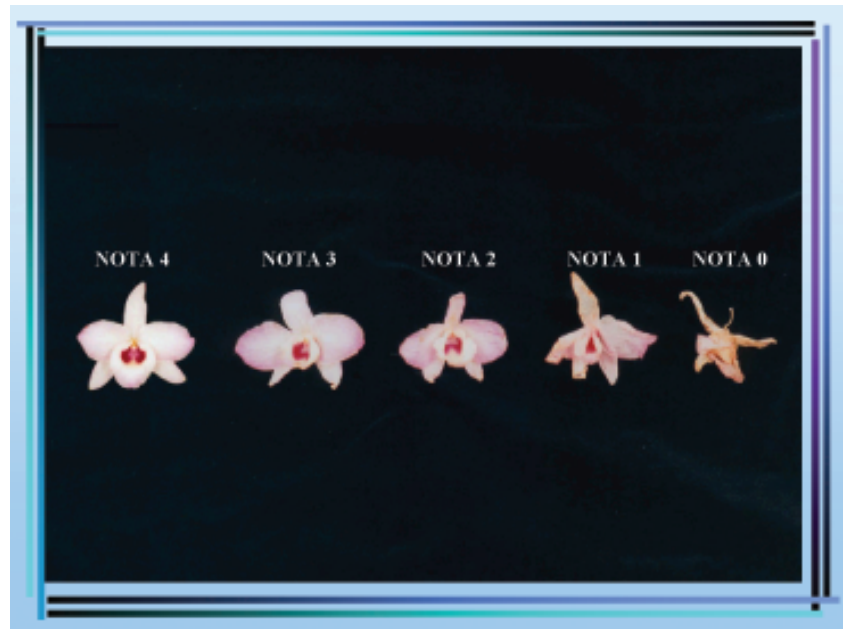

Figura 1. Critério de classificação por notas (CASTRO, 1984) para avaliação da longevidade das flores de Dendrobium nobile após a colheita dos pseudobulbos.

\section{RESULTADOS E DISCUSSÃO}

A longevidade das flores não foi influenciada pelas soluções conservantes (Tabela 1). Pode-se atribuir o fato à presença de carboidratos e água, especialmente no pseudobulbo, suficientes para suprirem a demanda energética das flores, o que está de acordo com PRITCHARD \& HEW (1998), ao descreverem que tais elementos desempenham importante papel durante o florescimento. Os resultados obtidos também reiteram a opinião de ASHMAN \& SCHOEN (1994), segundo o qual as flores de orquídeas apresentam grande longevidade.

O acúmulo de carboidratos pode ocorrer durante o crescimento da flor, na planta, ou ser fornecido por soluções preservativas (KETSA, 1989). STANCATO \& CEZARINO (2000), observaram que flores de Laelia purpurata Lindl. mantidas nas plantas tiveram maior longevidade que as cortadas, demonstrando o importante papel que o pseudobulbo exerce na manutenção da integridade da inflorescência. Nos tratamentos pós-colheita, concluíram que a adição de sacarose a $1 \%$ aumentou a longevidade das flores cortadas, o que foi igualmente observado por DIAS TAGLIACOZZO \& CASTRO (2001) com hastes florais de Phalaenopsis, tratando-as com solução contendo sacarose a $2 \%$. Neste trabalho, após a abertura, as flores mantiveram seu valor comercial até o décimo dia, de forma semelhante ao gengibre ornamental que não necessitou de tratamento pós-colheita, mantendo boa longevidade das inflorescências em água limpa (DIAS TAGLIACOZZO et al., 2001). 
Tabela 1. Avaliação dos tratamentos pós-colheita de pseudobulbos com flores de Dendrobium nobile, utilizando-se o critério de notas (CASTRO, 1984). O experimento foi realizado após cinco dias da abertura das flores

\begin{tabular}{|c|c|c|c|c|c|c|c|c|c|c|}
\hline \multirow{2}{*}{ Tratamentos } & \multicolumn{10}{|c|}{ Dias } \\
\hline & $6^{-}$ & $7^{\circ} \stackrel{0}{ }$ & $8^{\circ}$ & $9^{\circ}$ & $10^{\circ}$ & $11^{\circ}$ & $12^{\circ}$ & $13^{\circ}$ & $14^{\circ}$ & $15^{\circ}$ \\
\hline T1(água) & 3,67 & 3,60 & 3,35 & 3,10 & 2,45 & 2,42 & 2,00 & 1,57 & 0,90 & 0,37 \\
\hline T2 (sem água) & 3,72 & 3,72 & 3,52 & 2,90 & 2,72 & 2,20 & 1,92 & 1,67 & 1,20 & 0,55 \\
\hline $\mathrm{T} 3$ & 3,67 & 3,52 & 3,52 & 3,07 & 2,72 & 1,90 & 1,60 & 1,35 & 1,12 & 0,42 \\
\hline $\mathrm{T} 4$ & 3,82 & 3,75 & 3,75 & 3,25 & 2,55 & 2,42 & 2,05 & 1,57 & 1,32 & 0,60 \\
\hline T5 & 3,85 & 3,77 & 3,67 & 3,32 & 2,97 & 2,37 & 2,37 & 1,67 & 1,67 & 0,70 \\
\hline T6 & 3,82 & 3,80 & 3,75 & 3,30 & 2,90 & 2,60 & 2,20 & 1,65 & 1,32 & 0,65 \\
\hline $\mathrm{T} 7$ & 3,72 & 3,62 & 3,47 & 3,22 & 3,22 & 2,85 & 2,25 & 1,95 & 1,72 & 1,40 \\
\hline CV \% & 7,49 & 11,27 & 18,38 & 30,80 & 40,06 & 49,90 & 53,60 & 67,92 & 85,14 & 133,0 \\
\hline Médias & 3,75 & 3,69 & 3,54 & 3,13 & 2,75 & 2,36 & 2,04 & 21,63 & 1,31 & 0,71 \\
\hline
\end{tabular}

Os resultados não diferem entre si pelo teste de Tukey a 5\% de significância.

\section{CONCLUSÃO}

O tratamento com solução conservante contendo sacarose não proporcionou maior longevidade às flores de Dendrobium nobile .

\section{LITERATURA CITADA}

ASHMAN, T.L. \& SCHOEN, D.J. How long should flowers live? Nature, Londres, v. 371, p. 788-790, 1994.

CASTRO, C. E. F. Tratamentos químicos pós-colheita e critérios de avaliaçào de qualidade de cravos Dinthus caryophyllus cv. Scania Red Sim. Piracicaba: Escola Superior de Agricultura "Luiz de Queiroz”, 1984. 139p. Dissertação (Mestrado em Fitotecnia).

DIAS TAGLIACOZZO, G. M. \& CASTRO, C. E. F. Prolongamento da longevidade pós-colheita de Falenopse. In: CONGRESSO BRASILEIRO DE FLORICULTURAE PLANTAS ORNAMENTAIS, 13., São Paulo,. 2001a. Resumos... São Paulo, 2001. p.27.

DIAS TAGLIACOZZO, G. M.; ZULLO, M.A. \& CASTRO, C. E. F. Caracterização física e conservação pós-colheita de alpínia e gengibre ornamental. In: CONGRESSO BRASILEIRO DE FLORICULTURA E PLANTAS ORNAMENTAIS, 13., São Paulo. 2001b. Resumos... São Paulo, 2001. p.28.
FARIA, R. T. \& ILLG, R. D. Propagação clonal de híbridos de Dendrobium nobile. In: ENCONTRO BRASILEIRO DE BIOTECNOLOGIA VEGETAL, 1., Brasília, 1993. Resumos... Brasília, 1993. p.100.

HALEVY, A.H. Treataments to improve water balance of cut flowers. Acta Horticulturae, Aas. Sweden, v.64, p. 223230, 1976.

HALEVY, A.H. \& MAYAK, S. Senescence and post harvest physiology of cut flowers, Part I. Horticultural Reviews, New York, v. 1, p. 204-236, 1979.

KETSA, S. Vase-life characteristics of inflorescences of Dendrobium "Pompadour". Journal of Horticultural Science, Ashford Kent, v. 64, n. 5, p. 611-615, 1989.

LORENZI, H. \& SOUZA, H. M. Plantas ornamentais no Brasil. Nova Odessa: Ed Plantarum. 1996. v.1, p.650.

LORENZI, H. \& SOUZA, H.M. Plantas ornamentais no Brasil. Nova Odessa: Ed Plantarum. 2001. v.3. p.1088.

PRITCHARD, M.K. \& HEW, C.S. Sugar composition during flower opening and low temperature storage of Cymbidium orchid flowers. Lindleyana, West Palm Beach, v. 13, n.1, p. 6-10, 1998.

SILVA, W. Cultivo de orquídeas no Brasil. São Paulo: Nobel, 1986. p.96.

STANCATO, G. \& CEZARINO, F. Longevidade e durabilidade de flores de Laelia purpurata Lindl.. Rev. Bras. Hortic. Ornam., Campinas, v.6, n.1/2, p.69-74, 2000. 